УДК 622.276.8

ПРОБЛЕМЫ ПРОМЕЖУТОЧНЫХ СЛОЕВ

В НЕФТЕСБОРНЫХ РЕЗЕРВУАРАХ

\title{
PROBLEMS OF INTERMEDIATE LAYER IN OIL RESERVOIR
}

\author{
А.А. Фатыхова, В.У. Ямалиев \\ Уфимский государственный нефтяной технический университет, \\ г. Уфа, Российская Федерация \\ A.A. Fatychova, V.U. Yamaliev \\ Ufa State Petroleum Technological University, \\ Ufa, Russian Federation

\section{e-mail: sashafatychova@yandex.ru}

\begin{abstract}
Аннотация. На сегодняшний день проблема разрушения промежуточных слоев актуальна, так как углеводородная часть высокоустойчивых эмульсий является перспективным сырьем для получения широкого ассортимента нефтепродуктов. Накопление устойчивых промежуточных слоев в отстойных аппаратах со временем приводит к «срыву» технологического режима процесса подготовки нефти и воды. В работе представлены данные о составе, свойствах промежуточных слоев, проблемах, вызванных образованием устойчивых эмульсий, образующихся и накапливающихся в сырьевых резервуарах. Предложен наиболее оптимальный на сегодняшний день способ измерения размеров промежуточного слоя. Так как существующие способы разрушения высокоустойчивых эмульсий не позволяют получать нефтепродукты регламентируемого качества, предложена концепция мобильной установки для подавления эффекта устойчивости водонефтяных эмульсий промежуточного слоя. Установка позволит
\end{abstract}


применять для разрушения эмульсий не один метод, а их комбинации, индивидуально подобранные для промежуточных слоёв с различными свойствами исходя из анализа состава промежуточного слоя. Вывод застаревающей эмульсии из проектного технологического режима позволяет снизить производственные затраты при подготовке, a промежуточный слой, не достигший свойств застарелой эмульсии (нефтешлама), оперативно преобразовать мобильной установкой, режим работы которой оптимален для конкретного типа эмульсий. В установке применяются химический, ультразвуковой и электромагнитный методы разрушения. Применение комбинаций методов позволит максимально эффективно обрабатывать высокоустойчивые эмульсии и получать товарную продукцию высокого качества.

Abstract. Today, the problem of intermediate layers destruction is relevant, as the hydrocarbon part of highly resistant emulsions is a promising raw material for obtaining a wide range of petroleum products. The accumulation of stable intermediate phases in the settling apparatus over time leads to a «breakdown» of the technological regime of the process of oil and water treatment. The work presents data on the composition, properties of intermediate layers, problems caused by the formation of stable emulsions formed and accumulated in the raw material reservoirs. The most optimal way to measure the size of the intermediate layer has been proposed. Since the existing methods of destruction of highly stable emulsions do not allow obtaining oil products of regulated quality, it is proposed the concept of a mobile unit to suppress the effect of the stability of oil-water emulsions of the intermediate layer. The unit will allow to use for emulsions destruction not only one method, but their combinations, individually selected for intermediate layers with different properties, based on intermediate layer composition analysis. The withdrawal of the sticking emulsion from the design process mode allows reducing the production costs during treatment, and the field that did not achieve the properties of the old emulsion (oil sludge) quickly transform it by a mobile unit, the operating mode 
of which is optimal for a particular type of emulsion. The unit uses chemical, ultrasonic and electromagnetic methods of destruction. The use of combinations of methods will allow the most efficient processing of highly stable emulsions and the production of high quality products.

Ключевые слова: промежуточный слой, водонефтяная эмульсия, разрушение, обезвоживание, емкостное оборудование, измерение, методы разрушения, подготовка нефти

Key words: intermediate layer, water-oil emulsion, destruction, capacitive equipment, dehydration, measure, methods of the destructions, oil treatment

В процессе добычи нефти с водой образуются водонефтяные эмульсии. Они возникают из-за фильтрации и проникновения пластовой воды в призабойную зону добывающих скважин, смешения нефти и воды при движении по стволу скважины, интенсивного гидродинамического воздействия рабочих органов электропогружных и штанговых насосов, турбулизации потока в скважинной арматуре, разгазирования нефти при подъеме на поверхность [1]. При отстаивании водонефтяных эмульсий в резервуарах первичной установки подготовки нефти (УПН) образуются так называемые «промежуточные слои» между отделившимися слоями свободной нефти и воды [2].

Промежуточный слой - эмульсия, представляющая собой глобулы воды, окруженные адсорбированными на них частицами эмульгатора (так называемые стабилизаторы эмульсии) [3]. Главной составляющей стабилизаторов нефтяных эмульсий являются асфальтены. Находясь в сырой нефти в диспергированном состоянии, они концентрируются на поверхности раздела фаз, образуя защитную пленку. Этот процесс является необратимым.

Стойкость эмульсии обусловлена природными свойствами продукции скважин (наличием в составе нефти природных эмульгаторов и высокой 
коррозионной активностью пластовых вод) и в большей степени неудовлетворительной организацией эксплуатации месторождения, a именно:

- закачкой в пласт неочищенной речной воды и последующим бактериальным заражением пласта сульфатвосстанавливающими бактериями;

- чрезмерной интенсивностью закачки воды в пласт и, как следствие, суффозией пласта;

- отработкой скважин в систему нефтесбора после обработки призабойной зоны кислотами, приводящей к загрязнению нефти продуктами коррозии лифта скважин и трубопроводов системы нефтесбора;

- бесконтрольной откачкой жидкости из нефтяных амбаров кустов скважин, приводящей к загрязнению отстойных аппаратов илом и буровым раствором;

- отсутствием превентивных мер защиты от внутренней коррозии трубопроводов и оборудования агрессивными пластовыми водами;

- смешением продукции скважин разных продуктивных горизонтов в процессе добычи [4].

Важнейшими техническими проблемами промежуточных слоев являются повышенная устойчивость и вязкость. Промежуточный слой, содержащий значительное количество парафинов, смол, асфальтенов, механических примесей и стойкой эмульсии, снижает эффективность работы отстойников, уменьшая их полезный объем и препятствуя дренированию отделяемой воды. Он же является основным источником появления ловушечных нефтей на установках комплексной подготовки нефти (УКПН). Причина формирования ловушечных нефтей обусловлена тем, что с целью предотвращения чрезмерного накопления промежуточного слоя в отстойной аппаратуре их периодически сбрасывают в канализацию, откуда через очистные сооружения они 
перепускаются в амбары-шламонакопители. Наличие таких амбаров пагубно влияет на экологическую обстановку нефтегазодобывающих регионов [5].

Промежуточные слои негативно влияют и на экономические показатели. Подготовка скважинной продукции к транспорту является высокозатратным процессом. Он характеризуется высокой энерго- и металлоемкостью, что связано с необходимостью разрушения водонефтяных эмульсий. Так, на получение 1 т кондиционной нефти, отделяемой от продукции нефтяных скважин, расходуется до 106 кДж тепла [6]. Для сепарации скважинной продукции необходимо строить огромные наземные сооружения (резервуары, отстойники и др.).

В Постановлении Кабинета Министров Республики Татарстан об утверждении целевой программы «Система химической и биологической безопасности Республики Татарстан на 2012-2014 годы» отмечено, что наличие промежуточных слоев вызывает не только технологические, экономические, но и экологические проблемы. В актуальном документе отмечается, что ни один из известных методов обезвоживания не может разрушить все виды эмульсий. Следует учесть, что объемы образующихся промежуточных слоев составляют от нескольких сотен до нескольких ТЫсяч тонн в год.

Чтобы снизить отрицательное влияние промежуточных слоев на окружающую среду, необходимо постоянно сбрасывать их в амбарышламонакопители и перерабатывать. После переработки промежуточных слоев остаток (нефтешлам) необходимо утилизировать. [7]. Для минимального загрязнения окружающей среды нефтешламами необходимы новые технологии утилизации промежуточных слоев.

Из-за малой изученности промежуточных слоев отсутствует технология их качественной переработки. Одной из основных причин срыва технологического режима работы УПН и ухудшения качества 
получаемой нефти является накопление на границе раздела фаз промежуточного слоя.

Таким образом, на сегодняшний день проблемы, связанные с промежуточными слоями, не решены в полной мере и требуют дополнительных исследований. Целями данной работы являются детальное изучение механизмов образования, причин повышенной устойчивости и структуры промежуточного слоя, образующегося при отстаивании водонефтяных эмульсий.

Изучив проблему образования высокоустойчивых эмульсий и существующий опыт применения различных технологий предотвращения образования и разрушения промежуточных слоёв, сделан вывод, что ни один из существующих методов разрушения промежуточных слоев не позволяет получать из высокоустойчивых стабилизированных эмульсий конечные продукты регламентируемого качества, но позволяют комбинации этих методов [8]. Вывод застаревающей эмульсии из проектного технологического режима позволяет снизить производственные затраты при подготовке, а промежуточный слой, не достигший свойств застарелой эмульсии (нефтешлама), оперативно преобразовать мобильными техническими установками, режим работы которых оптимален именно для такого типа эмульсий. Это позволит избежать экономических потерь и экологических проблем, имеющихся при накапливании и сбросе нефтешламов.

Путем современных достижений отечественной науки и накопленной базы исследований в области изучения данного вопроса, нами предлагается концепция мобильной установки для подавления эффекта устойчивости водонефтяных эмульсий промежуточного слоя.

В силу того что сбои технологического режима с поступлением устойчивых водонефтяных эмульсий носят периодический характер, предлагается мобильная установка. В случае варианта мобильной установки, она размещается на автоприцепе и позволяет оперативно 
перемещать ее к требуемому резервуару и с помощью гибких рукавов подсоединять к аппаратам, установка энергонезависима.

В установке будут использованы: электромагнитный, акустический и химический методы. Это позволит применять для разрушения эмульсий не один метод, а их комбинации, индивидуально подобранные для промежуточных слоёв с различными свойствами, исходя из анализа состава промежуточного слоя. Применение комбинаций методов позволит максимально эффективно обрабатывать высокоустойчивые эмульсии и получать товарную продукцию высокого качества.

Принципиальная схема мобильной установки приведена на рисунке 1.

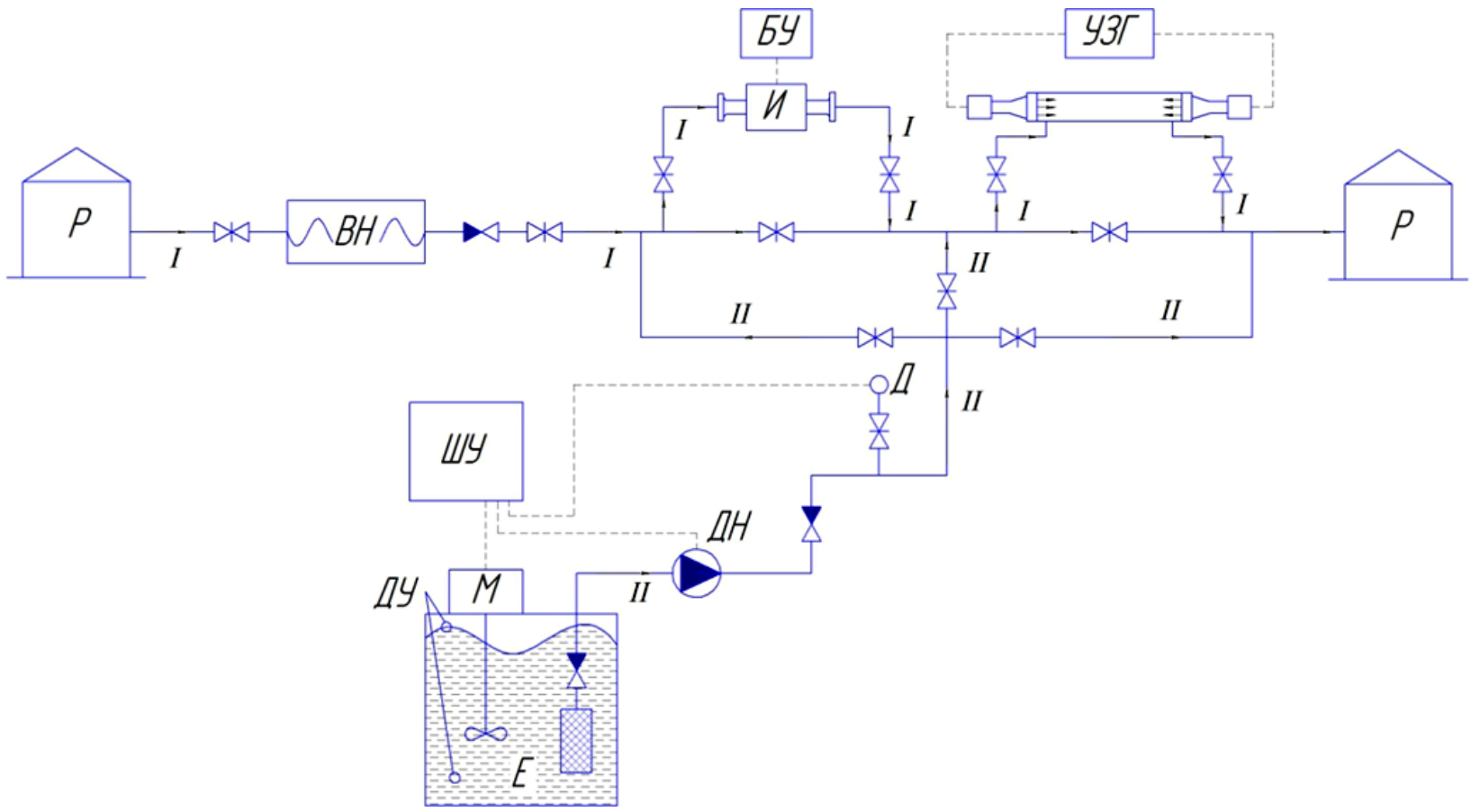

P - резервуар; ВН - винтовой насосный агрегат; И - индуктор электромагнитной установки; БУ - блок управления электромагнитной установкой; УЗГ - ультразвуковой генератор; ШУ - шкаф управления установкой дозирования реагента; ДУ - датчик уровня; М - мешалка; ДН - дозировочный насос; Е - технологическая емкость

Рисунок 1. Принципиальная схема установки для разрушения промежуточных слоев

Принцип работы предлагаемой установки заключается в следующем: при накоплении промежуточного слоя в резервуаре на УПН его откачивают через гибкие рукава с помощью винтового насосного агрегата. 
Конструкция установки предусматривает применение задвижек, что позволит обрабатывать промежуточный слой любой комбинацией методов разрушения эмульсий, в зависимости от свойств промежуточного слоя.

Для разрушения промежуточного слоя он может быть направлен в индуктор электромагнитной установки или ультразвуковой аппарат. Частота электромагнитного поля устанавливается на блоке управления электромагнитной установкой, выходная мощность ультразвукового аппарата регулируется на ультразвуковом генераторе, в зависимости от свойств эмульсии.

На любом этапе обработки в зависимости от свойств эмульсии может подаваться реагент для обработки химическим методом. Реагент подается специализированной установкой дозирования реагентов (УДР), оборудованной технологической емкостью, перемешивающим устройством, дозировочным насосом и датчиком уровня.

Параметры установки зависят от диаметра проходного сечения трубопроводов установки. Для того чтобы выбрать диаметр проходного сечения, необходимо определиться, за какое время установка должна обрабатывать скопившийся промежуточный слой. На УПН применяются преимущественно резервуары $\mathrm{PBC} 5000$. С учетом технических характеристик резервуара, его размеров и средней высоты промежуточного слоя в данных резервуарах вычислен объем промежуточных слоёв в резервуаре, который составляет 860 м³.

Так как промежуточный слой обладает высокой вязкостью, то для его перекачки выбран двухвинтовой нефтяной насос.

На рисунке 2 представлена зависимость производительности насоса от времени перекачки промежуточного слоя. 


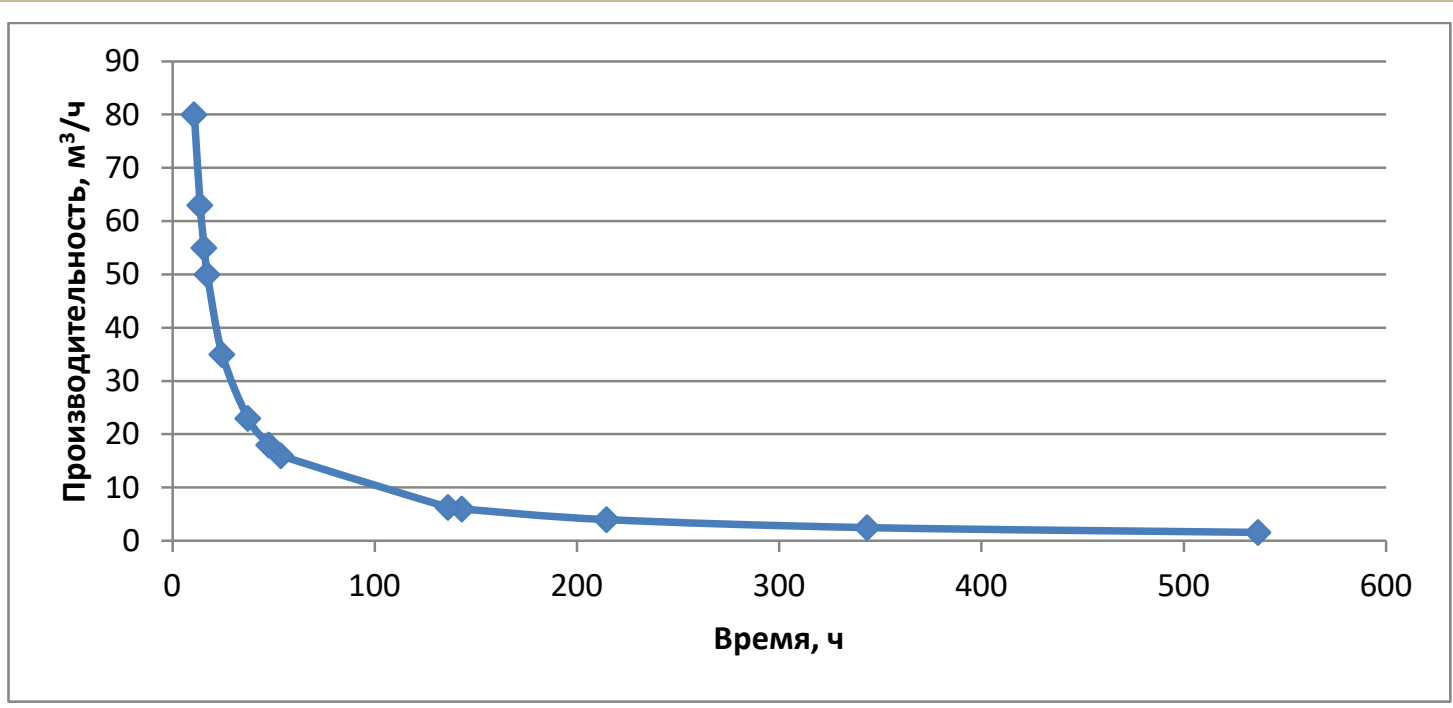

Рисунок 2. Время перекачки промежуточного слоя в зависимости от производительности насоса

Производительность насоса выбрана, исходя из времени перекачки эмульсии, оно не должно превышать 24 ч.

Например, при производительности насоса $80 \mathrm{~m}^{3} / \mathrm{ч}$ время прокачки промежуточного слоя минимально - 10,5 ч, но масса такого насосного агрегата достаточно велика для применения в мобильной установке. Поэтому выбираем насос производительностью $55 \mathrm{~m}^{3} / 4$, но меньшей массы, который перекачает рассчитанный объем промежуточного слоя за 15,6 ч, что приемлемо. Диаметр насоса на выходе - 100 мм. Насос комплектуется гибкими рукавами высокого давления с БРС диаметром 100 мM.

Выбраны параметры мобильной установки для применения различных методов разрушения эмульсий.

Для обработки промежуточных слоев электромагнитным методом потребуется изготовить индуктор с диаметром $3 \mathrm{~d}$ проходного сечения трубы, длиной 800 мм. Необходимый диаметр индуктора 300 мм.

Индуктор следует изготовить по примеру существующей установки УМП-108-014, разработанной по заданию ОАО «Белкамнефть» для обработки водонефтяной эмульсии Вятской площади Арланского месторождения. Включают индуктор, соединенный кабелем с блоком управления (рисунок 3 ). 


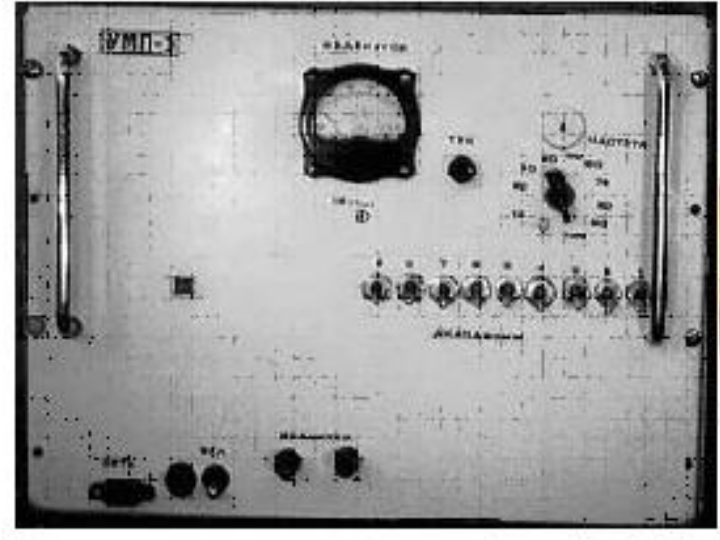

a)

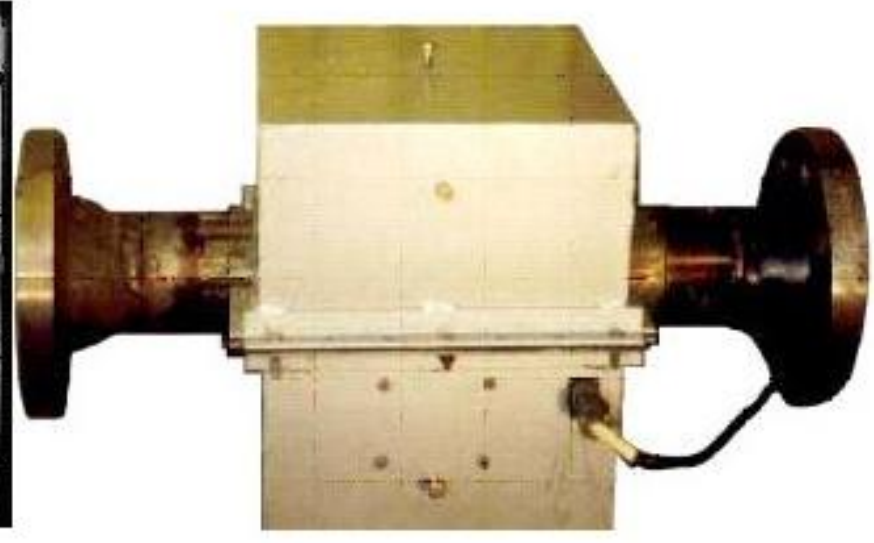

б)

а) блок управления; б) индуктор установки

Рисунок 3. Электромагнитная установка УМП-108-014

Индуктор состоит из магнитопровода, изготовленного из трансформаторного железа, между полюсами которого помещена труба из нержавеющей стали. Внутри трубы размещена вставка из трансформаторного железа - магнитный сердечник. Для возбуждения магнитного поля на полюса надеты катушки из провода. Блок управления состоит из генератора гармонических колебаний с 10 фиксированными частотами от 10 до 100 Гц, усилителя мощности и батареи конденсаторов.

Для обработки промежуточного слоя ультразвуковым методом используется устройство, представленное на рисунке 4. Устройство формирует поток эмульсий вода-нефть через область воздействия ультразвука вдоль направления потока. При этом создаются попутная ультразвуковая волна, направление распространения которой совпадает с направлением потока эмульсий, и противоточная ультразвуковая волна, направление распространения которой противоположно направлению потока эмульсий. После деэмульсификации эмульсии вода-нефть разделяют или осаждают для обезвоживания.

При применении устройства с продольной и противоточной ультразвуковыми волнами, при отстаивании под действием силы тяжести 
содержание воды в сырой нефти уменьшается на 50 \% по сравнению с устройствами с одной ультразвуковой волной.

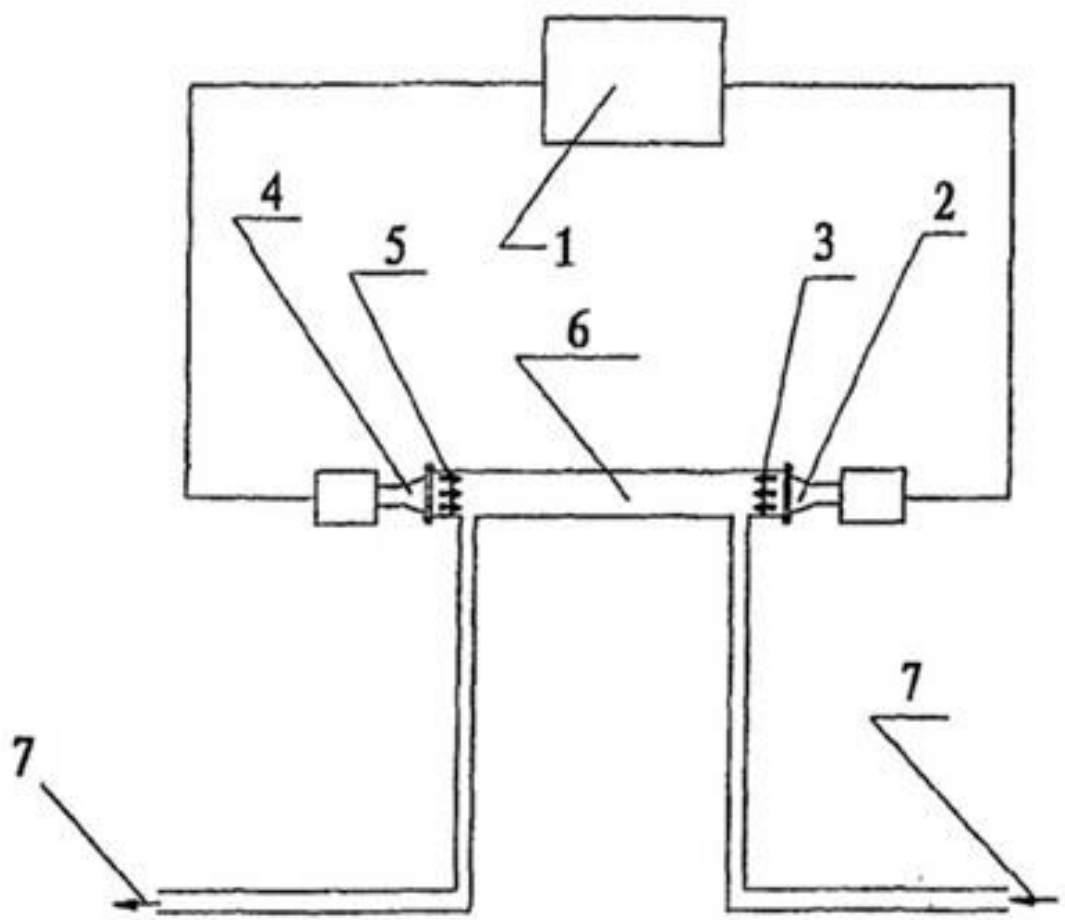

1 - ультразвуковой генератор; 2 - первый ультразвуковой преобразователь; 3 - попутная ультразвуковая волна; 4 - второй ультразвуковой преобразователь; 5 - противоточная ультразвуковая волна; 6 - область воздействия ультразвука; 7 - поток эмульсии вода-нефть

Рисунок 4. Принципиальная схема ультразвукового аппарата

Для применения химического метода разрушения промежуточного слоя выбрана установка дозирования реагента, укомплектованная насосомдозатором, емкостью для хранения реагентов с датчиком уровня, блоком контроля и управления с датчиком давления (рисунок 5).

Расход реагента в зависимости от свойств эмульсии и типа применяемого оборудования изменяется от 2,5 до $250 \mathrm{~cm}^{3} / \mathrm{M}^{3}$, средний расход составляет $50 \mathrm{~cm}^{3} / \mathrm{M}^{3}$. При вычисленном объеме промежуточных слоев $V_{\text {реагента }}=43$ л. Выбрана технологическая емкость $100 \mathrm{~m}^{3}$ для обеспечения запаса. 


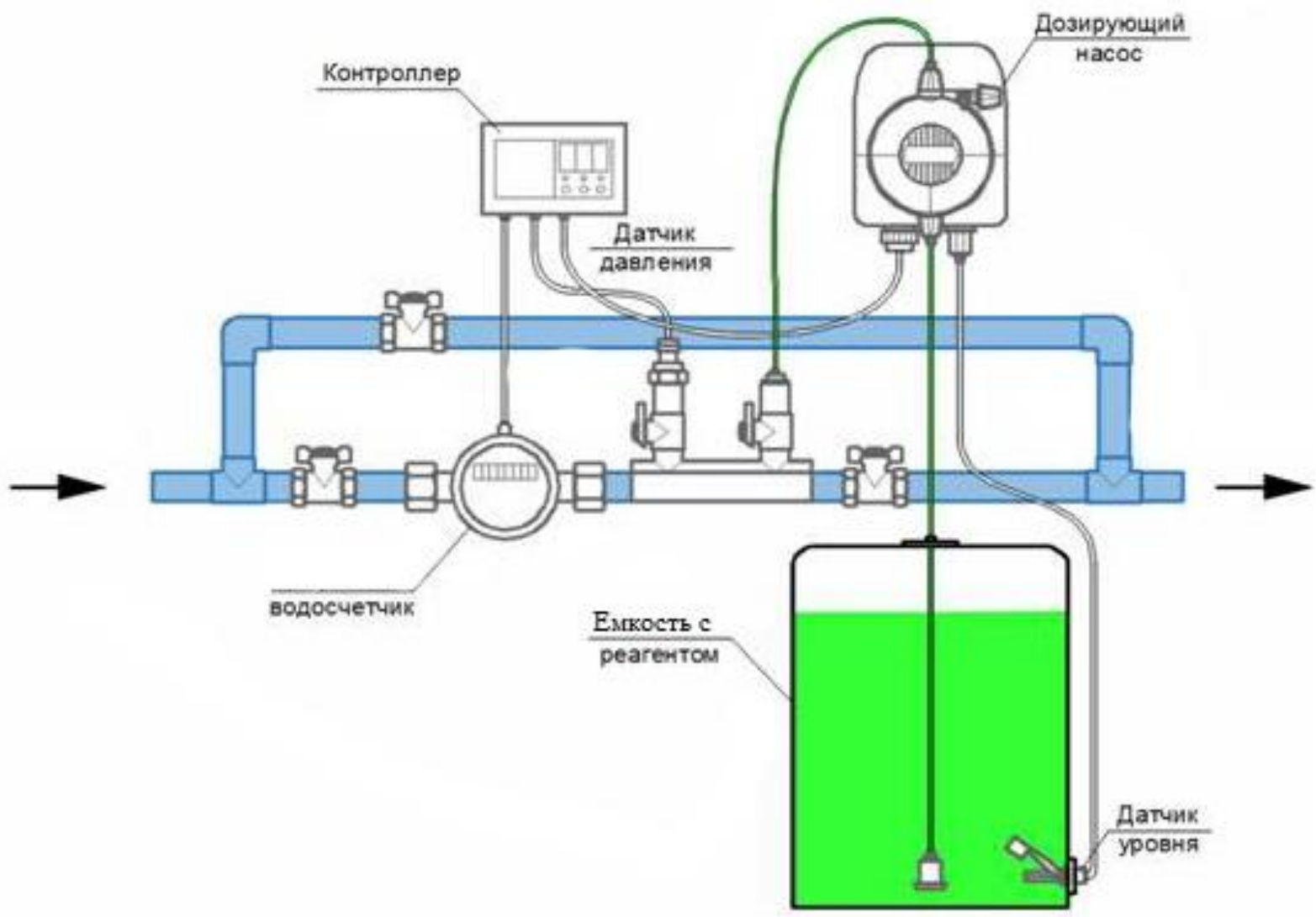

Рисунок 5. Схема установки дозирования реагентов

Изучив рынок установок дозирования реагента, преимущества и недостатки различных моделей, выбран блок дозирования реагентов типа УДЭ ТУ 3632-001-46919837-2009.

\section{Выводы}

Спроектирована мобильная установка для повышения эффективности разрушения промежуточных слоев, позволяющая применять различные комбинации методов разрушения высокоустойчивых эмульсий, включающая электромагнитную установку, аппарат ультразвукового воздействия и установку дозирования реагентов. Мобильная установка позволит максимально эффективно обрабатывать эмульсии и получать товарную продукцию высокого качества. 


\section{Список используемых источников}

1. Гумерова Д.М. Методы разрушения и предотвращения образования промежуточных слоев в технологическом оборудовании // Ученые записки Альметьевского государственного нефтяного института. 2012. Т. 10. № 1. C. 94-100.

2. Заббаров P.P. Разрушение высокоустойчивых эмульсий комбинированным методом // Известия высших учебных заведений. Серия: химия и химическая технология. 2007. Т. 50. № 6. С. 80-84.

3. Тюгаева Е.С., Долматов М.Ю. Причины образования устойчивых нефтяных эмульсий и способы их разруения // Universum: Технические науки. 2017. Т. 4. № 37. С. 64-69.

4. Фатхутдинов Б.Р., Фаттахова Г.Р. Исследование методов разрушения промежуточных слоев в ЦПНС «ПРОСВЕТ»// Вестник Казанского технологического института. 2016. Т. 19. № 5. С. 64-66.

5. Мамлеев Р.А., Мавлютова М.3., Комарова Н.М. Исследования условий формирования стойких эмульсий с повышенным содержанием механических примесей // Нефтепромысловое дело. 1980. № 10. С. 38-40.

6. Голубев М.В. Научные основы герметизированных технологий подготовки скважинной продукции на поздней стадии разработки нефтяных месторождений: дисс. ... д-ра техн. наук. Уфа: УГНТУ, 2006. $254 \mathrm{c}$.

7. Kimbler O.K., Reed R.L. Silberberg I.H. Physical Characteristics of Natural Films Formed at Crude Oil-Water-Interfaces // Society of Petroleum Engineers Journal. 1966. Vol. 6. No. 1. P. 153-165.

8. Reisberg J., Djsher T.M. Interfacial Phenomena in Crude-Oil-Water Systems // Prod Monthly. 1956. Vol. 21. 43 p. 


\section{References}

1. Gumerova D.M. Metody razrusheniya i predotvrashcheniya obrazovaniya promezhutochnykh sloev $\mathrm{v}$ tekhnologicheskom oborudovanii [Methods of the Destruction and Preventions of the Formation Intermediate Layers in Technological Equipment]. Uchenye zapiski Al'met'evskogo gosudarstvennogo neftyanogo institute - Proceedings of the Almetyevsk State Oil Institute, 2012, Issue 1, pp. 94-110. [in Russian].

2. Zabbarov R.R, Razrushenie vysokoustoichivykh emul'sii kombinirovannym metodom [Destruction of High-Stable Emulsions by the Combined Method]. Izvestiya vysshikh uchebnykh zavedenii. Seriya: khimiya I khimicheskaya tekhnologia - Russian Journal of Chemistry and Chemical Technology, 2007, Issue 6, pp. 80-84. [in Russian].

3. Tyugaeva E.S., Dolmatov M.Yu. Prichiny obrazovaniya ustoichivykh neftyanykh emul'sii i sposoby ikh razrueniya [Reasons of Stable Oil Emulsion Formation and Methods of Their Demulsification]. Universum: Tekhnicheskie nauki-Universum: Technical Sciences, 2017, Issue 37, pp. 64-69. [in Russian].

4. Fatkhutdinov B.R., Fattakhova G.R. Issledovanie metodov razrusheniya promezhutochnykh sloev v TSPNS «PROSVET». [Investigation of Methods of Destruction of Intermediate Layers in the CPSN «LUMEN»]. Vestnik Kazanskogo Tekhnologicheskogo Instituta - Bulletin of the Technological University, 2016, Issue 5, pp. 64-66. [in Russian].

5. Mamleev R.A., Mavlyutova M.Z., Komarova N.M. Issledovaniya uslovii formirovaniya stoikikh emul'sii s povyshennym soderzhaniem mekhanicheskikh primesei [Studies of the Conditions of Formation of Stable Emulsions with a High Content of Mechanical Impurities]. Neftepromyslovoe delo - Oilfield Engineering, 1980, Issue 10, pp. 38-40. [in Russian]. 
6. Golubev M.V. Nauchnye osnovy germetizirovannykh tekhnologii podgotovki skvazhinnoi produktsii na pozdnei stadii razrabotki neftyanykh mestorozhdenii: diss. dr. tekhn. nauk [Scientific Bases of the Sealed Technologies of Preparation of Well Production at a Late Stage of Development of Oil Fields: Dr. Engin. Sci. Diss.]. Ufa, UGNTU, 2006. 254 p. [in Russian].

7. Kimbler O.K., Reed R.L. Silberberg I.H. Physical Characteristics of Natural Films Formed at Crude Oil-Water-Interfaces. Society of Petroleum Engineers Journal, 1966, Vol. 6, No. 1, pp. 153-165.

8. Reisberg J., Djsher T.M. Interfacial Phenomena in Crude-Oil-Water Systems. Prod Monthly, 1956, Vol. 21, 43 p.

\section{Сведения об авторах}

\section{About the authors}

Фатыхова Александра Андреевна, магистрант кафедры «Машины и оборудование нефтегазовых промыслов», УГНТУ, г. Уфа, Российская Федерация

Aleksandra A. Fatychova, Undergraduate Student of Oil and Gas Field Machinery and Equipment Department, USPTU, Ufa, Russian Federation e-mail: sashafatychova@yandex.ru

Ямалиев Виль Узбекович, д-р техн. наук, профессор, заведующий кафедрой «Машины и оборудование нефтегазовых промыслов», УГНТУ, г. Уфа, Российская Федерация

Vil U. Yamaliev, Doctor of Engineering Sciences, Professor, Head of Oil and Gas Field Machinery and Equipment Department, USPTU, Ufa, Russian Federation

e-mail: ngpo_ugntu@mail.ru 